\title{
Thermal neutron activation cross section for ${ }^{48} \mathrm{Ca}$
}

\author{
Guilherme S. Zahn ${ }^{1, a}$, Cibele B. Zamboni ${ }^{1}$, Laura C. Oliveira ${ }^{1}$, and Frederico A. Genezini ${ }^{2}$ \\ Instituto de Pesquisas Energéticas e Nucleares, C.P. 11049, 05422-970 São Paulo SP, Brazil \\ 2 Centro Regional de Ciências Nucleares - CRCN-CNEN/PE, Brazil
}

\begin{abstract}
In this work several certified standard samples with very well-determined Calcium amounts were irradiated in the IEA-R1 nuclear reactor, under a thermal neutron flux of $\sim 10^{12} \mathrm{n} \cdot \mathrm{cm}^{-2} \cdot \mathrm{s}^{-1}$. The samples were then analyzed in a high-resolution gamma spectrometer in order to determine the amount of ${ }^{49} \mathrm{Ca}$ produced in the sample which, in turn, is directly proportional to the thermal neutron absorption cross section for ${ }^{48} \mathrm{Ca}$. These results allowed the determination of this cross section with an uncertainty that's $6 \times$ lower than the compiled value and approximately half the uncertainty of the best value found in the literature, thus improving the results that can be obtained when measuring Calcium via semi-parametric Neutron Activation Analysis.
\end{abstract}

\section{Introduction}

Recent studies have been pointing out many advantages of the semi-parametric NAA technique (ANAA), a variant of k0-NAA [1], in elemental analysis [1-6]; the main advantage of this technique towards the more usual INAA (Instrumental Neutron Activation Analysis) method is due to the fact that the latter requires certified standard samples to be irradiated together with the interest material at all times, thus making the analysis more expensive and time-consuming.

The ANAA technique, though, requires good knowledge of all the parameters involved in the activation calculation, as cross sections, isotopic abundances, detector efficiency, absolute $\gamma$-ray intensities, and so on. While for most isotopes and elements these parameters are very well determined, resulting in overall activation uncertainties that cope well with the ones obtained from INAA, in some extraordinary cases this may not be the case, so the ANAA results may present uncertainties that greatly surpass the ones from INAA.

One such case, and possibly the most important when dealing with biological samples, is Calcium. In this specific case, the most naturally abundant isotopes can't be used for neutron activation, as their irradiation result in stable nuclei, which are clearly not suitable for this purpose, so the most suitable reaction for the NAA measurement of Calcium is ${ }^{48} \mathrm{Ca}(\mathrm{n}, \gamma)^{49} \mathrm{Ca}$. In this case, though, the rarely-abundant $(\sim 0.1 \%){ }^{48} \mathrm{Ca}$ isotope presents relatively high uncertainties in both the neutron capture cross section and isotopic abundance.

The determination of the isotopic abundance of ${ }^{48} \mathrm{Ca}$ has always been plagued by the natural unstability in the abundance of the most abundant Calcium isotope, ${ }^{40} \mathrm{Ca}$, which is constantly being produced by the decay of the naturallyocurring radioative isotope ${ }^{40} \mathrm{~K}$; recently though, the NIST [9] has proposed a new methodology to determine the abundance of the Calcium isotopes, which results in new reference values with much lower uncertainties

On the other hand, the compiled and recommended value for the cross section for the ${ }^{48} \mathrm{Ca}(\mathrm{n}, \gamma)^{49} \mathrm{Ca}$ reaction is $(1.09 \pm$ $0.14)$ b [7], with an uncertainty over $12 \%$, probably as a side

\footnotetext{
${ }^{a}$ Presenting author, e-mail: gzahn@ipen.br
}

effect of the large uncertainty in the recommended abundance value by the time the compilation was done (1981). One measurement was found in the literature [8] that used $77.87 \%$ enriched ${ }^{48} \mathrm{CaCO}_{3}$ samples, resulting in a value of $(0.982 \pm$ $0.046) \mathrm{b}$. Thus, in order to both confirm this value and possibly reduce even further the uncertainty, a new measurement was performed, using natural Calcium.

\section{Experimental procedure}

For the determination of the cross section for ${ }^{48} \mathrm{Ca}$, samples with 20-150 mg of four different standard reference materials (NIST 1400 Bone Ash, NIST 1486 Bone Meal, NIST 1573A Tomato Leaves and NIST 8414 Bovine Muscle Powder) were irradiated in the IEA-R1 reactor, under a thermal neutron flux of approximately $10^{12} \mathrm{n} \cdot \mathrm{cm}^{-2} \cdot \mathrm{s}^{-1}$, for 180 seconds. In order to precisely determine the neutron flux, two Gold foils $(\sim 800 \mu \mathrm{g}$ each), one bare and one Cadmium-covered, were irradiated together with each sample.

After irradiation, the samples and the Gold foils were separately $\gamma$-counted in a system composed of a $198 \mathrm{~cm}^{3}$ HPGe detector connected to a standard spectroscopy amplifier and a MCA ADCAM module. The resulting spectra were then carefully analysed and the areas corresponding to the peaks of interest $\left(E_{\gamma}=3085 \mathrm{keV}\right.$ on the Calcium samples and $E_{\gamma}=412 \mathrm{keV}$ in the Gold samples) were determined using a model consisting of a gaussian summed up with a step function and an exponential tail; the background radiation was taken into account by subtracting a sourceless spectrum, taken subsequentially to the source measurement, from the spectrum to be analysed. The detection efficiency of the system was determined using a set of ${ }^{152} \mathrm{Eu},{ }^{133} \mathrm{Ba}$ and ${ }^{56} \mathrm{Co}$ standard sources.

The determination of the thermal neutron flux was made for each measurement by subtracting the epithermal flux, obtained from the activation of the Cadmium-covered Gold foil, from the total (thermal + epithermal) flux obtained from the activation of the bare Gold foil.

The thermal cross section $(\sigma)$ was then obtained from equation (1), where $A_{l}$ is net area under the interest peak, $M_{A}$ 
Table 1. Experimental results for the thermal neutron absortion cross section for ${ }^{48} \mathrm{Ca}$.

\begin{tabular}{|c|c|}
\hline sample & $\begin{array}{l}\text { cross section } \\
\text { (barn) }\end{array}$ \\
\hline NIST 1400 Bone Ash & $0.97 \pm 0.04$ \\
\hline NIST 1400 Bone Ash & $0.97 \pm 0.03$ \\
\hline NIST 1400 Bone Ash & $0.91 \pm 0.07$ \\
\hline NIST 1400 Bone Ash & $0.95 \pm 0.09$ \\
\hline NIST 1400 Bone Ash & $1.03 \pm 0.09$ \\
\hline NIST 1400 Bone Ash & $0.97 \pm 0.09$ \\
\hline NIST 1486 Bone Meal & $1.05 \pm 0.07$ \\
\hline NIST 8414 Bovine Muscle Powder & $1.09 \pm 0.18$ \\
\hline NIST 8414 Bovine Muscle Powder & $1.12 \pm 0.21$ \\
\hline NIST 8414 Bovine Muscle Powder & $1.01 \pm 0.18$ \\
\hline NIST 1573A Tomato Leaves & $0.99 \pm 0.09$ \\
\hline weighted average & $0.979 \pm 0.020$ \\
\hline
\end{tabular}

Table 2. Comparison of the previously available values for the thermal neutron absortion cross section of ${ }^{48} \mathrm{Ca}$ to the present result.

\begin{tabular}{lll}
\hline & $\begin{array}{l}\text { cross section } \\
\text { (barn) }\end{array}$ & $\begin{array}{l}\text { uncertainty } \\
(\%)\end{array}$ \\
\hline ref. [7] & $1.09 \pm 0.14$ & 12.8 \\
ref. [8] & $0.982 \pm 0.046$ & 4.68 \\
Present Work & $0.979 \pm 0.020$ & 2.01 \\
\hline
\end{tabular}

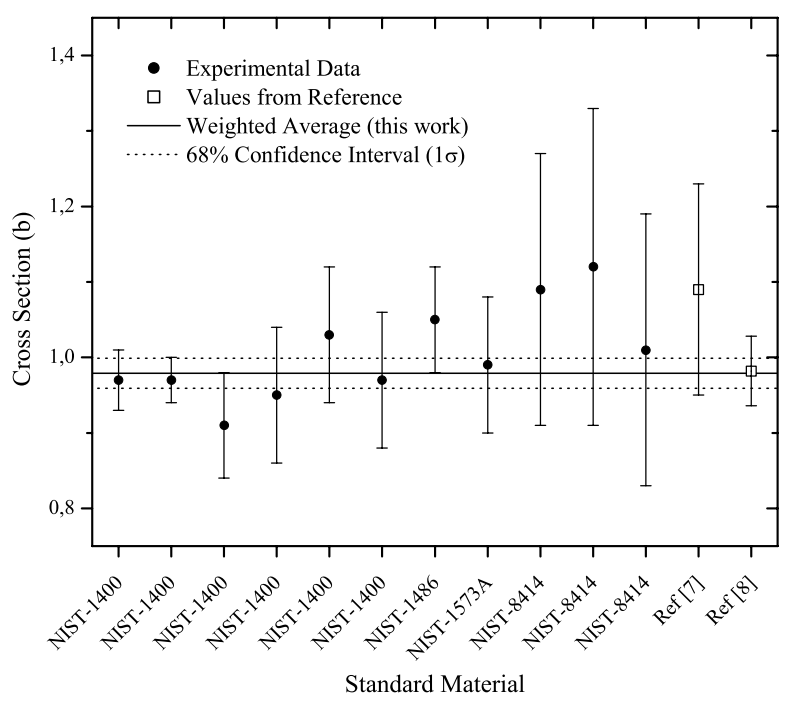

Fig. 1. Results for the thermal neutron absortion cross section for ${ }^{48} \mathrm{Ca}$ obtained in this work compared to the previously availabe values.

is the atomic mass, $\lambda$ is the decay constant, $N_{A}$ is Avogadro's number, $\phi$ is the thermal neutron flux, $F_{m}$ is the mass fraction of the interest element in the sample, $m$ is the sample mass, $I_{\gamma}$ is the intensity of the chosen $\gamma$-ray, $\epsilon$ is the system's detection efficiency for the energy of that $\gamma$-ray, $F_{I}$ is the isotopic abundance of the interest isotope, $T_{i}$ is the irradiation time, $T_{e}$ is the time elapsed between the end of the irradiation and the start of the counting and $T_{c}$ is the counting time.

$$
\sigma=\frac{\lambda A_{l} M_{A}}{\phi \epsilon m N_{A} F_{m} I_{\gamma} F_{I}\left(1-e^{-\lambda T_{i}}\right)\left(1-e^{-\lambda T_{c}}\right) e^{-\lambda T_{e}}} .
$$

\section{Results and discussion}

The results from the independent measurements are presented in table 1, together with their respective uncertainties; the last line shows the weighted $\left(\sigma^{-2}\right)$ average of these measurements. Table 2 compares the value obtained in this work and the values from references [7,8], and figure 1 compares the individual results obtained in this work to the previously available values, an also to the weighted average from this work and its uncertainty, showing that the present measurements are very reproductible and the value found for the ${ }^{48} \mathrm{Ca}$ cross section, while compatible with the previous data, presents a lower uncertainty.

\section{Conclusions}

In this work the thermal neutron absorption cross section for ${ }^{48} \mathrm{Ca}$ was determined as $0.979(20) \mathrm{b}$; this result, while in perfect agreement with the values found on reference $[7,8]$, was determined with a much better accuracy, resulting in an uncertainty about $2.0 \%$ (which is $16 \%$ of the uncertainty of the compiled value and $44 \%$ of uncertainty of the best value so far), and thus should allow much more precise results for the determination of Calcium using the ANAA technique.

\section{References}

1. C.B. Zamboni, L.C. Oliveira, L. Dalaqua Jr., J. Mesa, J. Radioanal. Nucl. Chem. 269, 331 (2006).

2. L.C. Oliveira, C.B. Zamboni, G.S. Zahn, M.P. Raele, M.A. Maschio, Braz. J. Phys. 34, 811 (2004).

3. L.C. Oliveira, C.B. Zamboni, F.A. Genezini, A.M.G. Figueiredo, G.S. Zahn, J. Radioanal. Nucl. Chem. 236, 783 (2005).

4. L.C. Oliveira, C.B. Zamboni, J. Mesa, J. Radioanal. Nucl. Chem. 269, 541 (2006).

5. L.C. Oliveira, C.B. Zamboni, P.S. Lins, M.R. Azevedo, Braz. J. Phys. 35, 793 (2005).

6. I.M.M.A. Medeiros, C.B. Zamboni, J.A.G. de Medeiros, M.A. Rizzutto, N. Added, M.H. Tabacniks, Braz. J. Phys. 35, 814 (2005).

7. S.F. Mughabghab, M. Divadeenam, N.E. Holden, Neutron Cross Sections from Neutron Resonance Parameters and Thermal Cross Sections (Academic Press, London, 1981).

8. H. Beer, C. Coceva, P.V. Sedyshev, Y.P. Popov, H. Herndl, R. Hofinger, P. Mohr, H. Oberhummer, Phys. Rev. C 54, 2014 (1996).

9. T.B. Coplen, J.K. Bohlke, P. DeBievre, T. Ding, N.E. Holden, J.A. Hopple, H.R. Krouse, A. Lamberty, H.S. Peiser, K. Revesz, S.E. Rieder, K.J.R. Rosman, E. Roth, P.D.P. Taylor, R.D. Vocke Jr., Y.K. Xiao, Pure Appl. Chem. 74, 1987 (2002). 